\title{
Impact of bio-physical feedbacks on the tropical climate in coupled and uncoupled GCMs
}

\author{
Jong-Yeon Park • Jong-Seong Kug • \\ Hyodae Seo $\cdot$ Jürgen Bader
}

Received: 5 June 2013/ Accepted: 22 November 2013/Published online: 28 December 2013

(C) Springer-Verlag Berlin Heidelberg 2013

\begin{abstract}
The bio-physical feedback process between the marine ecosystem and the tropical climate system is investigated using both an ocean circulation model and a fully-coupled ocean-atmosphere circulation model, which interact with a biogeochemical model. We found that the presence of chlorophyll can have significant impact on the characteristics of the El Niño-Southern Oscillation (ENSO), including its amplitude and asymmetry, as well as on the mean state. That is, chlorophyll generally increases mean sea surface temperature (SST) due to the direct biological heating. However, SST in the eastern equatorial Pacific decreases due to the stronger indirect dynamical response to the biological effects outweighing the direct thermal response. It is demonstrated that this biologicallyinduced SST cooling is intensified and conveyed to other tropical-ocean basins when atmosphere-ocean coupling is taken into account. It is also found that the presence of chlorophyll affects the magnitude of ENSO by two
\end{abstract}

J.-Y. Park · J. Bader

Max Planck Institute for Meteorology, Hamburg 20146,

Germany

J.-Y. Park

International Max Planck Research School On Earth System

Modelling, Hamburg 20146, Germany

J.-S. Kug ( ()

Korea Institute of Ocean Science and Technology, PO Box 29,

Ansan, Seoul 425-600, South Korea

e-mail: jskug1@gmail.com

H. Seo

Woods Hole Oceanographic Institution, Woods Hole,

MA 02543, USA

J. Bader

Geophysical Institute, University of Bergen, Bergen, Norway different mechanisms; one is an amplifying effect by the mean chlorophyll, which is associated with shoaling of the mean thermocline depth, and the other is a damping effect derived from the interactively-varying chlorophyll coupled with the physical model. The atmosphere-ocean coupling reduces the biologically-induced ENSO amplifying effect through the weakening of atmospheric feedback. Lastly, there is also a biological impact on ENSO which enhances the positive skewness. This skewness change is presumably caused by the phase dependency of thermocline feedback which affects the ENSO magnitude.

Keywords ENSO - Tropical mean climate . Biological feedback

\section{Introduction}

Phytoplankton, aquatic photosynthetic organisms, are known as a key player in the global biogeochemical system as well as in forming the base of the marine food chain. Although marine phytoplankton biomass amounts to less than $2 \%$ of the total global plant carbon, they account for nearly half of the global carbon fixation every year (Field et al. 1998; Behrenfeld et al. 2001). In fact, an observational study showed that a phytoplankton bloom in the upper ocean can induce a significant drawdown of atmospheric carbon dioxide $\left(\mathrm{CO}_{2}\right)$, implying the existence of ocean biology-induced climate feedback from a geochemical viewpoint (Chavez et al. 1999).

In addition, phytoplankton can also have a geophysical impact on the climate system. Chlorophyll and related pigments in phytoplankton absorb solar radiation in the blue and red frequencies and therefore affect the vertical distribution of radiant heating in the ocean (Lewis et al. 
1990; Strutton and Chavez 2004). Generally, water with phytoplankton traps more shortwave radiation in the upper layer than that without phytoplankton, which leads to enhanced surface warming and subsurface cooling. This biological modification of the shortwave energy penetration can influence the upper ocean thermal structure and has potential implications for climate variability as well as biologically induced thermal and dynamical processes.

Bio-physical processes have been considered to be a non-negligible factor in the upper ocean heat budget and in simulating tropical climate variability. Consequently, stateof-the-art global circulation models (GCM) have started to implement biological elements to the parameterization of the shortwave penetration processes. Historically, the penetration of shortwave radiation had been determined only by physical properties of seawater and was computed by splitting the total surface irradiance into two wavelength bands, infrared and visible bands (Paulson and Simpson 1977). In each of the wavelength bands, the shortwave radiation was assumed to be exponentially decaying with depth. By modifying the decay scales, the shortwave attenuation can be expressed as a function of chlorophyll concentration, which is one of the dominant attenuators of shortwave radiation in the open sea (Morel 1988). In a recent chlorophyll-dependent bio-optical scheme incorporated into GCMs, the shortwave penetration was further modified to consider the self-shading effect caused by the presence of phytoplankton (Manizza et al. 2005).

The development of such shortwave penetration schemes, together with the improvement of biogeochemical models coupled with GCMs, enables us to diagnose and quantify the bio-physical interactions by isolating the contributions of mean chlorophyll and the interactively varying chlorophyll to the climate system. So far, there have been multiple attempts to access the biological impacts on the physical fields (Sathyendranath et al. 1991; Nakamoto et al. 2000; Murtugudde et al. 2002; Timmermann and Jin 2002; Ohlmann 2003; Strutton and Chavez 2004; Wetzel et al. 2006; Lin et al. 2008; Gnanadesikan and Anderson 2009; Jochum et al. 2010; Turner et al. 2011). In particular, because the biological feedback can induce significant physical perturbations in the equatorial Pacific, this region has been an active research area for these studies. The reason these bio-physical interactions are significant in the equatorial Pacific can be traced to the combination of large equatorial chlorophyll concentration, strong shortwave radiation, and relatively high sensitivity to atmospheric feedback.

Previous modeling works, exploiting models ranging from simple to complex coupled physical-biogeochemical models, clearly showed that the effect of chlorophyll matters not only for the mean state but also for the El Niño/ Southern Oscillation (ENSO) variability. For example, studies using simplified coupled atmosphere-ocean models reported a reduction in ENSO magnitude in response to increased chlorophyll concentrations (Timmermann and Jin 2002; Zhang et al. 2009). Specifically, Timmermann and Jin (2002) showed that changes in the shortwave absorption profile within the mixed layer intensify the asymmetry of ENSO, and suggested that the negative biological feedback may compensate for the systematic bias of sea surface temperatures (SSTs) in current climate models. Ocean global circulation models (OGCMs) including bio-optical processes also found a connection between chlorophyll concentrations and tropical SST by showing a mean SST change and/or an amplification of the seasonal cycle due to the inclusion of biological processes (Murtugudde et al. 2002; Gildor and Naik 2005; Manizza et al. 2005; Sweeney et al. 2005; Lin et al. 2007). A recent study using an OGCM coupled to a biogeochemistry model further examined the biologically-induced climate feedback in the equatorial Pacific and established that the indirect dynamical response to the inclusion of biological processes outweighs the direct thermal response (Loptien et al. 2009).

The atmosphere-ocean coupled global circulation models (CGCMs) incorporating marine biology have also shown that biological feedback can significantly change the modeled climatology and variability (Marzeion et al. 2005; Wetzel et al. 2006; Anderson et al. 2007; Ballabrera-Poy et al. 2007; Lengaigne et al. 2007; Jochum et al. 2010; Lin et al. 2011; Patara et al. 2012). For example, Marzeion et al. (2005) showed that the presence of chlorophyll leads to a deepening of the mixed layer in the eastern equatorial Pacific due to the biologically enhanced subsurface warming. Further, they showed that the biological feedback onto the mean state can change significantly when atmosphere-ocean coupling is taken into account. Recently, Jochum et al. (2010) quantified the biological feedback on the ENSO amplitude and found a $9 \%$ reduction of ENSO variability occurs in a fully active ecosystem experiment relative to an experiment using prescribed climatological chlorophyll.

Despite considerable modeling work on this subject, the aforementioned studies on the biological feedback show somewhat contradictory results (Table 1). For example, some studies reported that the presence of chlorophyll derives an increased mean SST in the eastern equatorial Pacific due to enhanced absorption of shortwave radiation and/or deepening of the mixed layer that leads to reduced upwelling (Murtugudde et al. 2002; Marzeion et al. 2005; Wetzel et al. 2006). On the other hand, surface cooling caused by an indirect dynamical response to the biologically enhanced heating has been also reported (Nakamoto et al. 2001; Manizza et al. 2005; Loptien et al. 2009; Jochum et al. 2010). Similar to these conflicting results on the mean state changes, biological impacts on ENSO found in 
Table 1 Representative studies on the bio-physical feedbacks in the tropical Pacific using different model designs

\begin{tabular}{|c|c|c|c|c|}
\hline & \multicolumn{2}{|c|}{ (FULLBIO or CLIMBIO) - (NOBIO) "Impact by mean chlorophyll" } & \multicolumn{2}{|c|}{$\begin{array}{l}\text { (FULLBIO) }-(\text { CLIMBIO }) \\
\text { "Impact by interactive } \\
\text { chlorophyll" }\end{array}$} \\
\hline & Warm & Cool & Warm & Cool \\
\hline $\begin{array}{l}\text { Eastern } \\
\text { equatorial } \\
\text { Pacific } \\
\text { Mean SST }\end{array}$ & $\begin{array}{l}\text { Marzeion et al. (2005), Wetzel et al. } \\
\text { (2006), Murtugudde et al. } \\
\text { (2002), Patara et al. (2012) }\end{array}$ & $\begin{array}{l}\text { Nakamoto et al. (2001), Manizza et al. (2005), Lin } \\
\text { et al. (2007), Loptien et al. (2009), Gnanadesikan } \\
\text { and Anderson (2009), Anderson et al. (2009), Jochum } \\
\text { et al. (2010), Lin et al. (2011) }\end{array}$ & $\begin{array}{l}\text { Lengaigne et al. } \\
\text { (2007) }\end{array}$ & \\
\hline \multirow{2}{*}{$\begin{array}{l}\text { ENSO } \\
\text { Magnitude }\end{array}$} & Intensified & Weakened & Intensified & Weakened \\
\hline & $\begin{array}{l}\text { Marzeion et al. (2005), Loptien } \\
\text { et al. (2009), Anderson et al. } \\
\text { (2009) }\end{array}$ & Timmermann and Jin (2002), Wetzel et al. (2006) & $\begin{array}{l}\text { Lengaigne et al. } \\
\text { (2007), } \\
\text { Loptien et al. } \\
\text { (2009) }\end{array}$ & $\begin{array}{l}\text { Jochum } \\
\text { et al. } \\
\text { (2010) }\end{array}$ \\
\hline
\end{tabular}

"FULLBIO" indicates the experiments using interactive biogeochemistry model coupled to a physical model. "CLIMBIO" indicates the experiments using climatological chlorophyll concentration (or fixed chlorophyll) either from the observations or from the FULLBIO experiments to estimate biological heating in the ocean. "NOBIO" experiments use the clear water assumption referring to the ocean either with low phytoplankton or without phytoplankton. Studies in italized use the coupled general circulation model (CGCM), while bold faced studies use the ocean general circulation model (OGCM)

previous studies also show that biophysical feedback can either amplify the ENSO response (Marzeion et al. 2005; Lengaigne et al. 2007; Loptien et al. 2009), or dampen it (Timmermann and Jin 2002; Wetzel et al. 2006; Jochum et al. 2010).

Although a direct intercomparison between all of the aforementioned studies is difficult due to the many different modeling strategies used, such diverse results on the effects of biological feedback processes reflect our insufficient knowledge on this subject. As noted in previous studies, in particular, there are competing biological feedback processes on both the mean and variability of climate in the equatorial Pacific, involving the mean chlorophyll concentration, the structure of horizontal and/ or vertical chlorophyll distribution, and the interannual variations in the chlorophyll (Marzeion et al. 2005; Lengaigne et al. 2007; Park et al. 2012). In this regard, different biological feedback processes and the predominance of one specific process may alter the consequences of bio-physical coupling, and perhaps even change its sign. Furthermore, most of previous studies use only a stand-alone ocean model or a fully coupled model, so that it is not easy to identify whether the contradicting biological impacts on the physical state are due to the presence of atmosphere-ocean coupling or some other factors. In fact, such contradictory results are acknowledged to be a possible impact of atmospheric feedback. However different biological responses have even been found in CGCM studies as shown in Table 1. Therefore, further investigation and more documentation are still needed in order to develop a better understanding and resolution of the role that bio-physical feedbacks play in modifying the physical state.
In this study, bio-physical feedback processes have been examined using both an ocean GCM and a fully-coupled ocean-atmosphere GCM, which are coupled with a stateof-the-art biogeochemical model. In each model experiment, the biological components of the ocean shortwave heating is either calculated from the biogeochemical model or externally prescribed. Thus, this approach with uncoupled and coupled model simulations in terms of air-sea coupling and bio-physical coupling provide a top-down view of the biological impacts on the mean state and climate variability. The region of interest here is the tropical Pacific where the strong variability appears both in the biological and physical fields and significant implications for the global climate can be expected.

\section{Description of observations and models}

\subsection{Observational data}

The primary observational data used in this study are satellite-retrieved chlorophyll concentrations derived from Sea-viewing Wide Field-of-view Sensor (SeaWiFS) and Moderate Resolution Imaging Spectroradiometer (MODIS) (Esaias et al. 1998; McClain et al. 1998). These two data sources provide a multi-year record of global phytoplankton spanning the time period September 1997 to December 2010. This record is comprised of SeaWiFS data from September 1997 to December 2007, and MODIS data from January 2008 to December 2010 obtained from the Goddard Space Flight Center. The sensors detect water-leaving radiance across the visible spectrum, particularly in the chlorophyll absorption band. Thus, the optical measurement 
from the satellite sensors can be used to estimate chlorophyll concentrations and infer phytoplankton standing stocks within the euphotic zone (Morel and Berthon 1989). A comparison study between this remotely-sensed satellite data and in situ chlorophyll data showed very good agreement in the open sea (Sobel et al. 2002).

For computational efficiency, the original data, which was binned to a grid of $9 \mathrm{~km} \times 9 \mathrm{~km}$, have been re-gridded onto a $2.5^{\circ} \times 2.5^{\circ}$ grid using the bi-linear interpolation method. Since ocean chlorophyll concentrations present a nearly log-normal distribution (Campbell 1995), the median value in each grid is used in the interpolation process.

The observational SST used to evaluate the model performance with respect to the biologically-related physical variations is from the Extended Reconstructed SST version 3 (ERSST v3) derived from in situ measurements, with a spatial resolution of $2.0^{\circ} \times 2.0^{\circ}$ (Smith et al. 2008). We use the data for the 60 year period from 1951 to 2010 to match the period of the model simulations.

\subsection{Numerical models}

The model used in this study is the Geophysical Fluid Dynamics Laboratory (GFDL) Climate model version 2.1 (CM2.1), consisting of a land model (LM2.1), an atmospheric model (AM2.1), a Modular Ocean Model Version 4 (MOM4p1), and a Sea Ice Simulator (SIS) (Alexander and Scott 2002). These separate components interact through a flux coupler module. This fully coupled model has been used for climate change experiments in the third and fifth phase of the Coupled Model Inter-comparison Project (CMIP3/CMIP5).

The horizontal resolution of the LM2.1 and AM2.1 is $2^{\circ}$ latitude $\times 2.5^{\circ}$ longitude on a regular grid, and the AM2.1 has 24 levels in a hybrid coordinate. The dynamical core of AM2.1 uses the finite volume method. For the MOM4p1, the resolution is $1^{\circ}$ in latitude and longitude between $30^{\circ}$ and $65^{\circ}$, and telescopes to $1 / 3^{\circ}$ toward the equatorial region. The latitudinal resolution of MOM4p1 in the polar region is non-uniform, refining towards the poles in a Mercator-like fashion; that is, the horizontal grid switches from spherical to bipolar poleward of $65^{\circ}$ using grid factors from Murray (1996). There are 50 vertical levels in the ocean component with 22 levels of $10-\mathrm{m}$ thickness in the upper ocean layer and expanding to about $350 \mathrm{~m}$ in the deep ocean. The ocean model uses a three-dimensional $\mathrm{z}$-coordinate numerical representation of the hydrostatic primitive equations, employing the Boussinesq approximation and an explicit free surface. Detailed descriptions of the MOM4p1 model can be found in Griffies et al. (2009).

In this study, we used an ocean biogeochemical model coupled to a physical circulation model, called Tracers of Phytoplankton with Allometric Zooplankton (TOPAZ) model (Geider et al. 1996; Dunne et al. 1999, 2005). This model represents the ecological cycling by considering 25 tracers, including three phytoplankton groups, dissolved organic matter, heterotrophic biomass, and dissolved inorganic species. While the growth rates of all phytoplankton functional groups are co-limited by light, nitrogen, phosphorus and iron with flexible physiology, each group has its own parameter set to determine growth rates and its own nutrient stoichiometry. Chlorophyll, the focus of this study, is diagnostically calculated using a coupled stoichiometric ratio and the nutrients in different planktonic types. Chlorophyll concentration, in turn, is used in the shortwave absorption scheme to define the absorption for the MOM4p1 model. A key feature of this model is the parameterization of phytoplankton loss through a size-based relationship and the time-lagged grazing rate by zooplankton; that is, unlike other phytoplankton groups, the grazing on the large phytoplankton is calculated using an implicit concentration after a temperature-dependent time lag, which mimics the observed zooplankton life cycles. This TOPAZ model has been tested against global nutrient and satellite observations both in MOM4p1 and CM2.1, and has shown a reasonable performance in simulating observational bio-physical properties (Henson et al. 2009; Gnanadesikan et al. 2011).

In our model experiments, the optical routine used for estimating shortwave penetration, which computes the impact of chlorophyll on the optical properties of ocean water, is the Manizza optics scheme (Manizza et al. 2005). The thickness and density weighted tendency of temperature associated with penetrative shortwave heating is computed from either specified chlorophyll data or the biogeochemical model. In this scheme, the shortwave radiation is computed at every vertical level of the model as a function of that level's chlorophyll concentration and the irradiance at the vertical level just above. Thus, this scheme includes the self-shading effect caused by the presence of phytoplankton in the overlying water column.

\subsection{Experimental design}

Three different experiments are performed using both OGCM and fully-coupled ocean-atmosphere model. In the first experiment, named as CHL.on, the biogeochemical model is turned on and the simulated chlorophyll is used to determine the penetration of shortwave radiation into the ocean. In the other two experiments, CHL.0 and CHL.clim, the biogeochemical model is turned off and the chlorophyll data used to calculate oceanic shortwave heating are externally prescribed. Specifically, in CHL.0 the chlorophyll is set to zero everywhere, while in CHL.clim the three-dimensional climatological chlorophyll concentration field (in longitude-latitude-depth) derived from CHL.on is used. Hence, compared to the other experiments, the ocean in CHL.0 is more transparent to shortwave radiation. Such 
Table 2 Summary of experiments

\begin{tabular}{llll}
\hline Name of experiment & Model used & Biological component & Simulation period \\
\hline OGCM_CHL.on & MOM4p1 + TOPAZ & Simulated chlorophyll & 60 years $\times 2$ \\
OGCM_CHL.0 & MOM4p1 & No chlorophyll & 60 years $\times 2$ \\
OGCM_CHL.clim & MOM4p1 & Climatological chlorophyll & 60 years $\times 2$ \\
CGCM_CHL.on & CM2.1 + TOPAZ & Simulated chlorophyll & 300 years \\
CGCM_CHL.0 & CM2.1 & No chlorophyll & 300 years \\
CGCM_CHL.clim & CM2.1 & Climatological chlorophyll & 300 years \\
\hline
\end{tabular}

The experiments are designed to evaluate the biological feedbacks by mean marine biology (CHL.clim - CHL.0) and the impact by interannually-varying biology (CHL.on - CHL.clim)

an experimental design enables us to assess the biological impacts on the physical state as a result of differing mean chlorophyll concentrations, and also to isolate the impact of interannual variability of chlorophyll from that due to mean chlorophyll. Moreover, by comparing the results from OGCM experiments and fully coupled experiments, the role of atmosphere-ocean coupling in affecting biophysical process can be evaluated.

The detailed descriptions of OGCM experiments and fully coupled experiments are as follows: In the OGCM experiments, all the experiments are hindcast-type runs forced by the observed 6-hourly winds during 1951-2010 obtained from the National Centers for Environmental Prediction/ National Center for Atmospheric Research (NCEP/NCAR) reanalysis I (Kalnay et al. 1996). For other boundary conditions, such as shortwave radiation, longwave radiation, near-surface specific humidity, precipitation and air temperature, monthly climatological data from the Common Ocean-Ice Reference Experiment (CORE) are used (Large and Yeager 2004). Runoff is prescribed by an annual average climatological value, and wet and dry dust depositions are given by the monthly climatology following Ginoux et al. (2001). This OGCM experimental design for the this study is similar to the that of Park et al. (2012) except using three dimensional chlorophyll data prescribed in CHL.clim. For the fully coupled experiments, three different runs (CHL.on, CHL.clim, and CHL.0) are performed, which are almost the same as those for the ocean-only experiments except using a fully interactive atmospheric model. In all experiments of the fully-coupled one, the model is integrated for 300 years after a 300 year of spin-up period, and the results from the last 250 -years of each run is used for analysis. The summarized experimental design is shown in Table 2.

\section{Results}

\subsection{Modeled biological component}

The simulated chlorophyll patterns of CHL.on are first compared to the satellite observations of chlorophyll
(Fig. 1). Although satellite-retrieved ocean color data is based on light reflected primarily from the ocean surface, some fraction is also backscattered from deeper parts of the mixed layer. Therefore, we use the average chlorophyll concentration over the upper $20 \mathrm{~m}$ to compare with the observational chlorophyll.

In the observations, mean chlorophyll is characterized by high concentration along the equator that generally increases eastward (Fig. 1a). The tropical Pacific is known to be a region where the phytoplankton growth is nutrientlimited. Because the equatorial upwelling in the cold tongue region can supply those materials, this leads to favorable conditions for the phytoplankton growth (Martin et al. 1994; Chavez et al. 1999). In the subtropics, however, the chlorophyll concentration is relatively low due to inactive vertical mixing and weaker upwelling. Similar to the mean pattern, chlorophyll variability also tends to be strong in the equatorial Pacific and coastal areas where high chlorophyll concentration appears (Fig. 1b). The horizontal pattern of surface chlorophyll variability reminds us of ENSO-related SST variability.

The biogeochemical model results (Fig. 1c-f) reasonably capture the main spatial features of the observed chlorophyll distribution (Fig. 1a, b). Despite the slight overestimation of modeled chlorophyll, the mean and variability of chlorophyll from both model and observation are quite similar, displaying higher chlorophyll concentrations in both the tropical and sub-polar Pacific and lower concentrations in the subtropics. The correlation coefficient between the observed chlorophyll and the ocean-only model results is significant at the $95 \%$ confidence level in the tropical Pacific. A more detailed description of the performance of the ocean-only model experiment is also documented in Park et al. (2012). Such a good performance of the biogeochemical model is encouraging. The realistic modeling of the biological response to physical variations is the essential prerequisite of this type of study, thus it can be expected to provide a more accurate diagnosis on the bio-physical coupling.

Comparing the results of the fully-coupled model with the ocean-only model, it shows that the coupled one predicts slightly higher chlorophyll levels (cf. Fig. 1c, d, e, f). 
(a) MEAN (Obs)

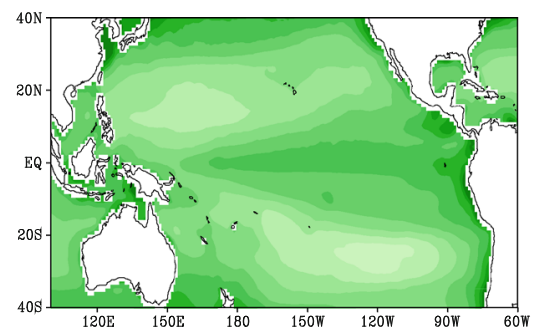

(b) STDV (Obs)

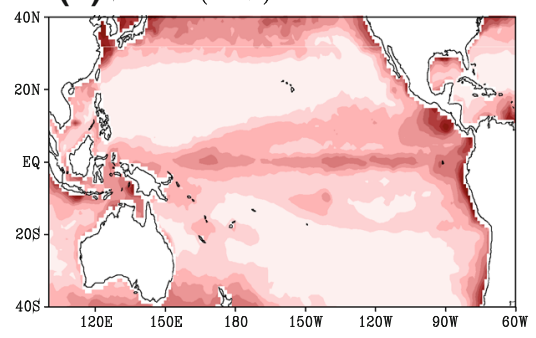

(c) MEAN (Coupled)

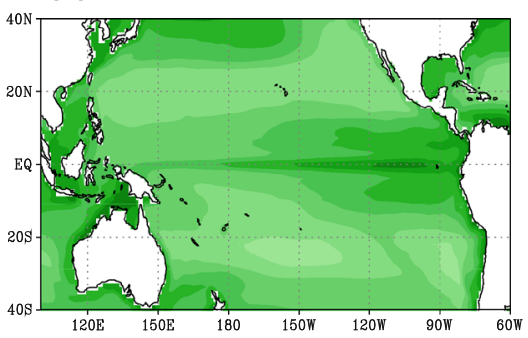

(d) STDV (Coupled)

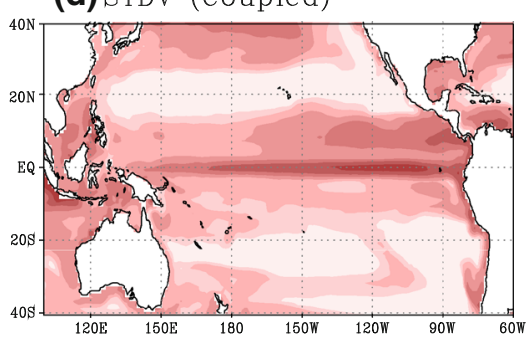

(e) MEAN (Ocean-only)

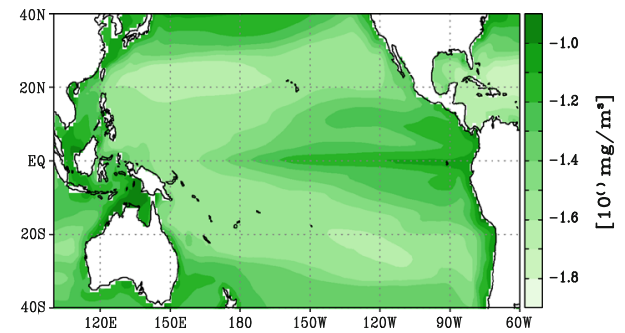

(f) STDV (Ocean-only)

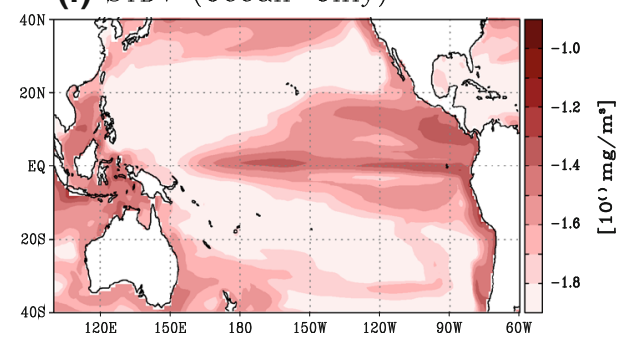

Fig. 1 a Mean and $\mathbf{b}$ standard deviation of chlorophyll concentration from the observations. $\mathbf{c}, \mathbf{d}$ and $\mathbf{e}, \mathbf{f}$ are same as $\mathbf{a}, \mathbf{b}$ from the fully-coupled model experiment and the ocean-only model experiment, respectively

This result is probably attributable to the stronger-thanobserved wind fields present in the fully coupled model (not shown). Note that the observed wind is used for the boundary forcing of the ocean-only model experiment. In general, stronger surface wind intensifies the vertical mixing and equatorial upwelling, which enhances nutrient supply to euphotic layer, which in turn, induces the higher mean chlorophyll in the full coupled experiment compared to the ocean-only experiment.

In order to further evaluate the performance of the biogeochemical model, the dominant modes of chlorophyll and associated SST patterns are analyzed from both model and observations. Previous studies reported that the first and the second mode of chlorophyll in the tropical Pacific are associated with the mature and decaying phases of ENSO cycle, respectively (Yoder and Kennelly 2003; Runge et al. 2006; Park et al. 2011).

Figure 2a-f are the spatial patterns of observed chlorophyll and SST, respectively, regressed onto the first principle components (PC) of tropical chlorophyll at 3 different time-lags. These figures are almost identical to Fig. 7a-f in Park et al. (2011) despite the use of newly updated ocean color products and an extended data period. The leading chlorophyll pattern at zero lag shows negative anomalies in the equatorial Pacific (Fig. 2a), and this pattern corresponds to the mature warm phase of ENSO (Fig. 2d). As the El Niño SST signal decays (Fig. 2e, f), negative chlorophyll anomalies are also reduced (Fig. 2a-c) and weak positive anomalies in chlorophyll appear along the equator at 6 months after the El Niño peak (Fig. 2c). These biological patterns are primarily affected by the modulation of nutrient supply driven by equatorial upwelling and the zonal advection of phytoplankton-rich water from the eastern equatorial Pacific (Picaut et al. 2001; Wilson and Coles 2005; Maes et al. 2010; Radenac et al. 2012).

These observational characteristics are also reproduced fairly well in the fully coupled model experiment (Fig. 2g-1). While the simulated chlorophyll anomalies appear in a narrower latitudinal band along the equator compared to the observations, the negative chlorophyll anomalies at the first mode of tropical chlorophyll and the evolution of the chlorophyll pattern associated with the ENSO cycle can also be found in the model result. Note that for the coupled model results we used different lag intervals for the lagged regression analysis because ENSO periods are not the same between the observations and the fully-coupled model results (observations and ocean model: 2-3 year, coupled model: $4-5$ year). The same figures for the ocean-only model experiments are more like the observations as shown by Park et al. (2012) and the detailed comparison between the observations and ocean-only model results is also documented in their study.

Given the overall modeling results of the biological variability modulated by ENSO, the observational characteristics are generally reproduced well in the model. Therefore, the use of the current model would be a reasonable choice for investigating the biological influence on the climate system in the tropical Pacific.

\subsection{Influence of marine biology on the mean climate}

It is known that, first, the presence of chlorophyll induces a surface warming and subsurface cooling through a 


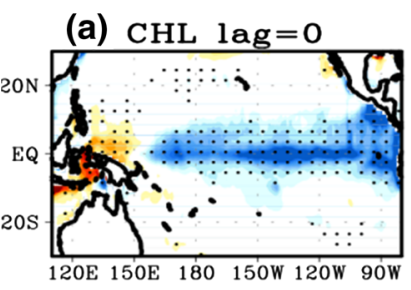

(b) $\mathrm{CHL}$ lag $=+3$

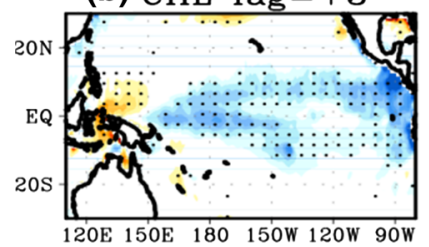

(c) $\mathrm{CHL}$ lag $=+6$

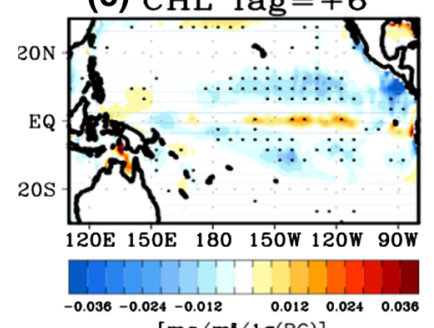

$[\mathrm{mg} / \mathrm{m} / / \mathbf{1} \sigma(P C)]$

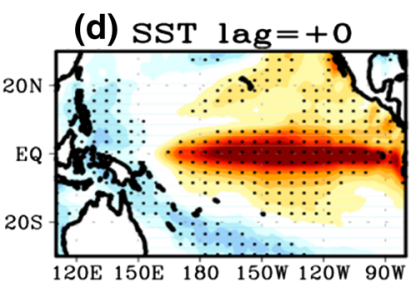

(e) $\mathrm{SST} \operatorname{lag}=+3$
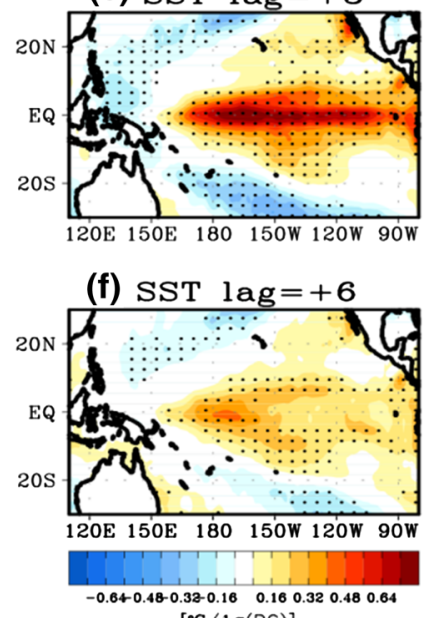

$\left[{ }^{\circ} \mathrm{C} / 1 \boldsymbol{\sigma}(\mathrm{PC})\right]$

Fig. 2 Lagged regressions of observed $\mathbf{a}-\mathbf{c}$ chlorophyll concentration and $\mathbf{d}-\mathbf{f}$ SST against the first leading principle component of tropical chlorophyll. $\mathbf{g}-\mathbf{i}$ and $\mathbf{j}-\mathbf{l}$ are same as $\mathbf{a}-\mathbf{c}$ and $\mathbf{d}-\mathbf{f}$ except using data

modification of shortwave absorption profile in the upper ocean (Lewis et al. 1990). This vertical redistribution of shortwave heating is the first basic assumption of biological feedback. As shown in Fig. 3, in the eastern equatorial Pacific, more shortwave heating is trapped in the upper ocean above $30 \mathrm{~m}$ depth and less shortwave heating appears below $30 \mathrm{~m}$ depth due to the vertically distributed chlorophyll. However, the secondary response of the physical state to the biologically-induced heating can modify or outweigh the initial direct thermal responses (Marzeion et al. 2005; Loptien et al. 2009). Moreover, as mentioned in the introduction, there is still a discrepancy in the biologically thermal feedback as previous studies have shown different results in terms of mean SST changes. In this section, a comprehensive intercomparison of mean SST is performed between two groups of experiments (fully coupled vs. ocean-only) in order to present the effect of air-sea coupling process on the relationship between mean SST and chlorophyll in the tropics.

\subsubsection{Eastern equatorial Pacific}

Figure 4 shows annual mean SST results along equator (meridional mean $5^{\circ} \mathrm{S}-5^{\circ} \mathrm{N}$ ). In the coupled model experiments, the mean SST appears to be higher in CHL.0 than in either CHL.on or CHL.clim (Fig. 4a). The SST
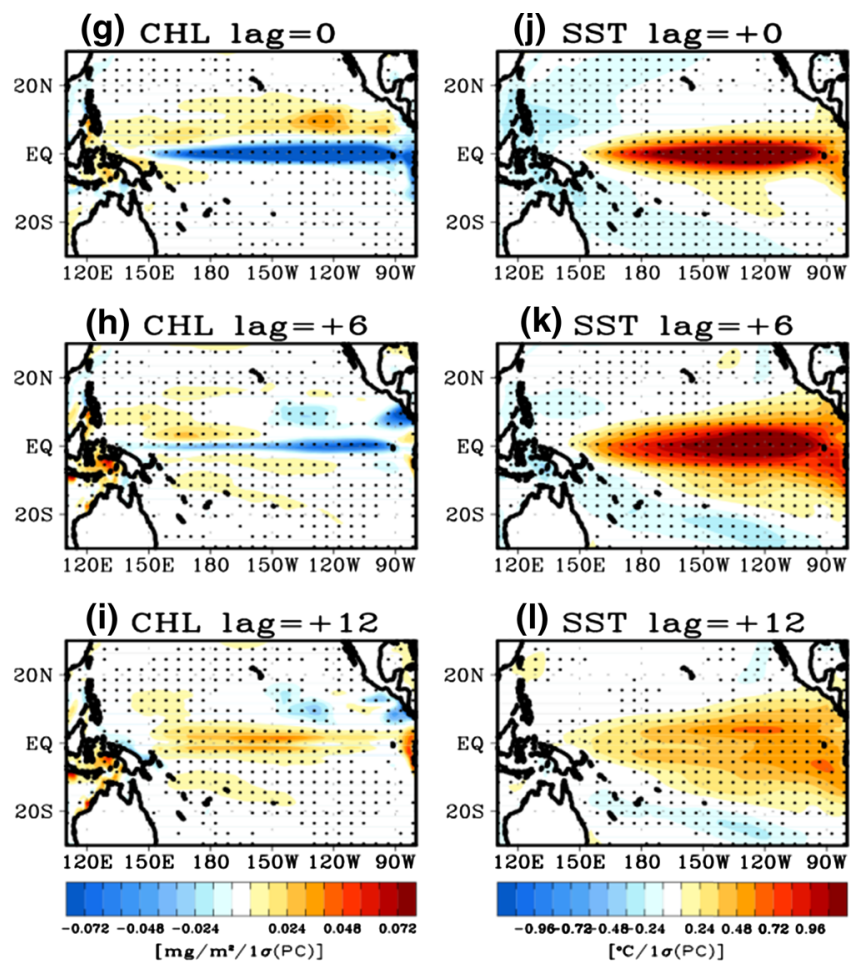

from fully-coupled experiment. Lag is in months. The stippled area denotes the $95 \%$ confidence region

difference between the experiments with and without chlorophyll is larger in the eastern equatorial Pacific than the western side. The mean SST difference in the eastern Pacific is stronger in late summer and early autumn when chlorophyll shows the maximum in a year. One thing to note here is that mean SSTs from CHL.on and CHL.clim are almost identical. Given that CHL.clim uses the monthly climatological chlorophyll field derived from CHL.on, it implies the chlorophyll time variations in interannual time scale have a negligible effect on the mean SST in the equatorial Pacific. A set of ocean-only model experiments has produced results similar to those in the fully-coupled model ones (Fig. 4b). CHL.0 shows the highest annual mean SST in the equatorial Pacific with the maximum difference being located in the eastern equatorial Pacific. Mean SSTs from CHL.on and CHL.clim again are almost indistinguishable as was seen in the results of the fullycoupled model experiments. However, the mean SST difference between the experiments with and without chlorophyll is much smaller in the ocean-only experiments than in fully-coupled model ones, which is probably due to the role of atmospheric feedback as discussed later.

The aforementioned biologically-induced differences at the ocean surface generally accompany changes in the thermal structure of ocean. In fact, it has been reported that the SST cooling and the thermocline shoaling are roughly 
Fig. 3 a Vertical profile of chlorophyll and b shortwave heating in the equatorial Pacific $\left(150^{\circ} \mathrm{W}-90^{\circ} \mathrm{W} ; 5^{\circ} \mathrm{S}-5^{\circ} \mathrm{N}\right)$ used in three different ocean-only experiments, CHL.on (blacksolid line), CHL.clim (greendotted line), and CHL.0 (bluedot-dashed line). The shortwave heating in $\mathbf{b}$ is presented as the difference from CHL.0 (a) $\mathrm{CHL}$

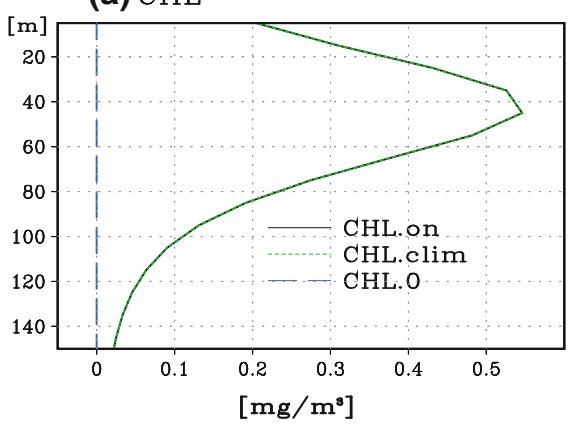

(b) SW_heat Diff

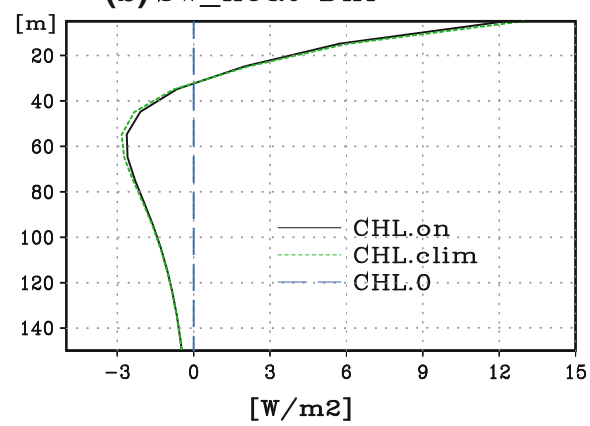

(a) Mean SST (Coupled)

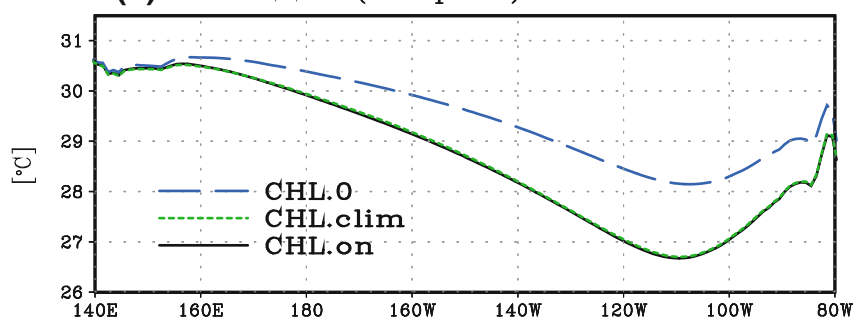

(c) THCD

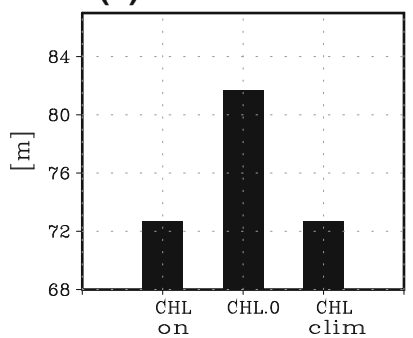

(d) $\mathrm{THCD}$
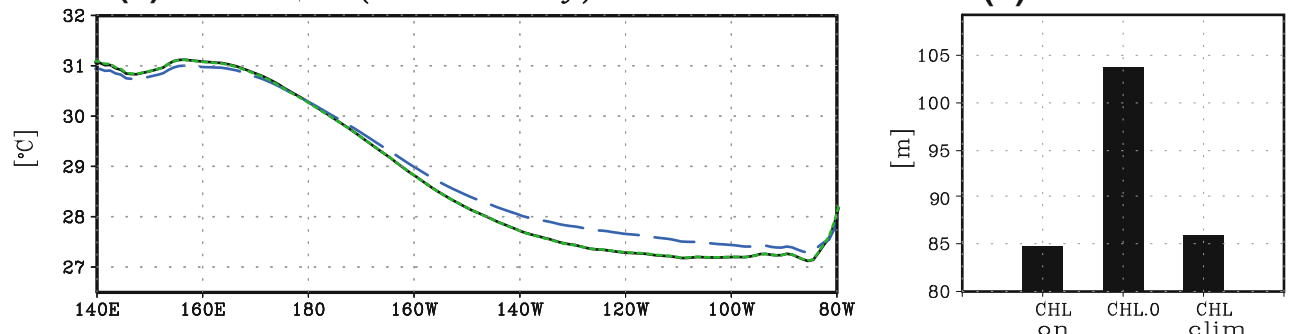

Fig. 4 Mean equatorial SST (averaged along the equator $5^{\circ} \mathrm{S}-5^{\circ} \mathrm{N}$ ) from the a fully-coupled experiments and the $\mathbf{b}$ ocean-only experiments. c, $\mathbf{d}$ are mean thermocline depth averaged in NINO3 region

proportional to the total amount of chlorophyll in the current model (Park et al. 2012). To check this, the mean thermocline depths from the different experiments are compared in the NINO3 region $\left(90^{\circ}-150^{\circ} \mathrm{W}, 5^{\circ} \mathrm{S}-5^{\circ} \mathrm{N}\right)$, where the maximum SST difference are detected (Fig. 4a, b). Here, the thermocline depth is defined as the depth of the maximum vertical gradient of ocean temperature (upper layer minus lower layer temperature). In accordance with the mean SST, the thermocline depth becomes significantly shallower when chlorophyll is included (CHL.on and CHL.clim) compared to when it is absent (CHL.0). Similarly, the differences between CHL.on and CHL.clim are not significant for both the ocean-only model and the fullycoupled model experiments. Similar features are also observed for the case of mixed layer depth (not shown).

The mechanisms of surface cooling with the presence of chlorophyll seen in Figs. 4a, 3b have been documented in previous studies (Sweeney et al. 2005; Loptien et al. 2009). The dominant mechanism described there was that the $\left(90^{\circ}-150^{\circ} \mathrm{W}, 5^{\circ} \mathrm{S}-5^{\circ} \mathrm{N}\right)$ from the coupled and ocean-only model experiments, respectively

vertical redistribution of shortwave heating by chlorophyll intensifies oceanic stratification, which induces the shoaling of the mixed layer, and leads to the enhanced equatorial upwelling due to the poleward volume transports. Park et al. (2012) also pointed out that the initial warming by the chlorophyll is replaced by subsurface cooling several years after the inclusion of chlorophyll.

Another important point to note is that the SST response to the biological heating can be amplified when atmospheric feedback is included. As shown in Fig. 4a, b, the SST difference between the coupled experiments with and without ocean biology is increased relative to that of the ocean-only model case. The maximum mean difference of SST between CHL.on and CHL. 0 is $\sim 1.5^{\circ} \mathrm{C}$ in the fullycoupled model experiments, while it is only $\sim 0.5{ }^{\circ} \mathrm{C}$ in the ocean-only model case. The intensified biological feedback by the presence of air-sea coupling is consistent with the results from Marzeion et al. (2005) despite the opposite sign in the SST response. Such amplification of the 
biologically-induced SST changes may arise from the atmospheric reinforcement of negative SST anomalies in the equatorial Pacific through the positive Bjerknes feedback. In the ocean-only model experiments, the biological feedback process is confined to the mixed layer as described in Sweeney et al. (2005). This is because all the experiments with the ocean-only model are forced by the same wind forcing, so that the atmospheric feedback cannot play a role in affecting the equatorial ocean dynamics. Hence, the center of anomalous upwelling appears within the mixed layer (Fig. 5b). In the coupled run, however, a cooling of the eastern equatorial Pacific can strengthen the trade winds which are associated with an enhanced equatorial upwelling via Ekman transport, which cools the eastern equatorial Pacific further. Because this wind-driven forcing induces a thermocline shoaling, the maximum of anomalous upwelling is deeper and stronger in the fully coupled model experiments than that in the ocean-only model experiments. Overall these results indicate that the positive air-sea feedback is an important component in terms of the magnitude of biological feedbacks influencing the mean SST in the tropical Pacific.

The present modeling study shows that the surface cooling when including the biological impacts is common in both the fully-coupled model and ocean-only model experiments, which is inconsistent with some previous studies. For example, Lengaigne et al. (2007) found that

(a) W Diff (Coupled)

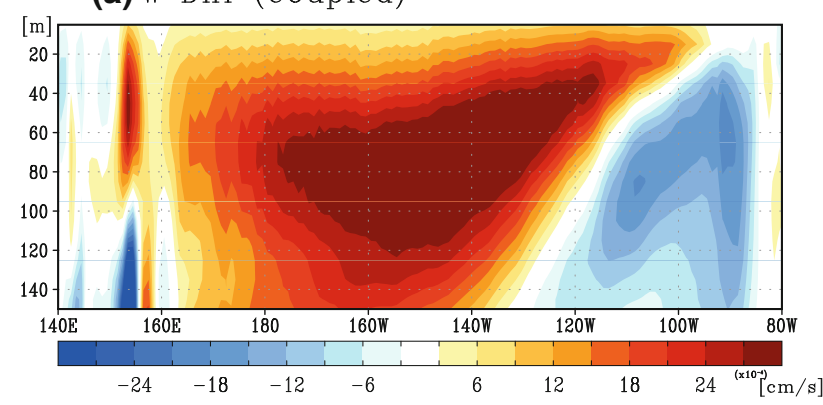

(b) W Diff. (Ocean-only)

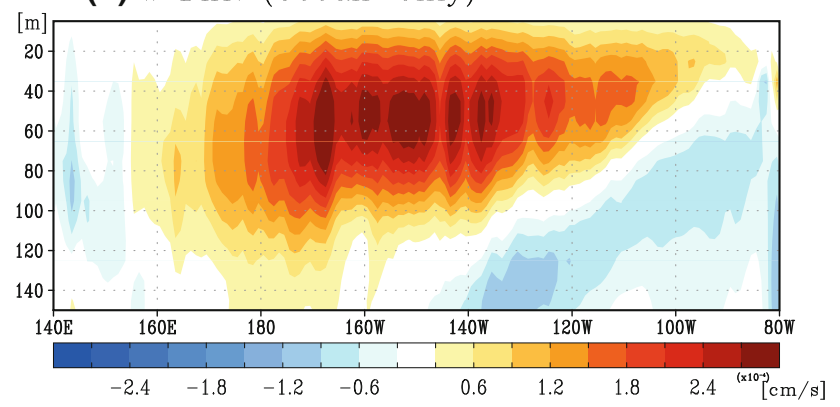

Fig. 5 Mean difference of vertical velocity at the equator (averaged $2^{\circ} \mathrm{S}-2^{\circ} \mathrm{N}$ ) between CHL.on and CHL.0 from the a fully-coupled experiment and $\mathbf{b}$ ocean-only experiment coupled ocean-atmosphere studies show a consistent SST warming in the eastern equatorial Pacific due to the atmospheric retroactions which generate positive SST anomalies. Far more complex reasons for the inconsistency could exist beyond the air-sea coupling effect alone.

\subsubsection{Other tropical oceans}

Besides the noticeable differences in biologically-induced SST cooling in the tropical Pacific, a striking difference between the fully-coupled and the ocean-only experiments also appears in the Atlantic and Indian Oceans (Fig. 6). In the fully-coupled model experiments, biologically induced surface cooling, while strongest in the Pacific, also appears to be significant in the Atlantic and Indian Oceans. However, in the ocean-only experiments, the biologically induced SST changes show weak surface warming in both the tropical Atlantic and Indian Ocean. Given the role of chlorophyll in enhancing the near-surface absorption of shortwave radiation, surface warming is generally expected to appear when including ocean chlorophyll. In this regard, the SST warming in the Atlantic and Indian Oceans for the ocean-only experiment can be explained by the inclusion of biologically-induced direct heating of the near-surface layer (This is not the case in regions where ocean dynamics plays a stronger role in the surface temperature, such as the equatorial eastern Pacific, the tropical Atlantic cold tongue, and the western Arabian Sea). However, because significant cooling occurs in the fully-coupled experiments when the effects of chlorophyll are included, another mechanism must be implicated in driving the SST changes.

The primary reason for the surface cooling could be changes in the heat flux between atmosphere and ocean, which is induced by the cooling of the entire tropical free troposphere in response to the eastern equatorial Pacific cooling (Alexander and Scott 2002; Chiang and Sobel

(a) SST Diff. (Coupled)

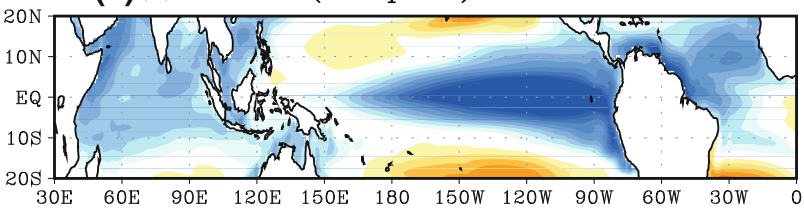

(b) SST Diff. (Ocean-only)

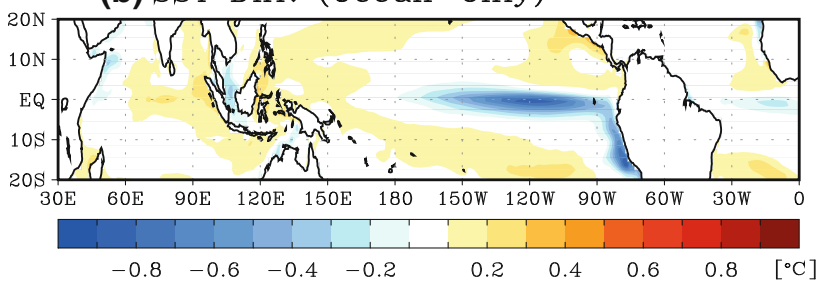

Fig. 6 Mean difference of SST between CHL.on and CHL.0 from the a fully-coupled experiment and the $\mathbf{b}$ ocean-only experiment 
2002). According to previous studies, tropical tropospheric temperature is significantly affected by mean tropical SST through a simple moist adiabatic relationship (Sobel et al. 2002). Moreover, the moisture-related atmospheric heating or cooling is quickly distributed in the tropics, so that strong horizontal temperature gradients cannot be maintained (Bretherton and Sobel 2003). The atmospheric cooling in the overall tropical troposphere, shown in Fig. $6 a$, can be explained by such a mechanism. In other words, the biologically-induced surface cooling over the eastern equatorial Pacific reduces the latent and sensible heat releases from the ocean, which then act as a heat sink for the tropical free troposphere. As a result, the atmospheric cooling quickly spreads throughout the tropical troposphere.

The positive latent and sensible heat fluxes (Fig. 7b) into the ocean in the eastern equatorial Pacific indicate a suppressed heat flux release from the ocean because of the negative SST anomalies. In particular, the latent heat flux plays a dominant role in the atmospheric cooling over the Pacific (Note the different vertical axis intervals: $10 \mathrm{~W} / \mathrm{m}^{2}$ for the latent heat and $1 \mathrm{~W} / \mathrm{m}^{2}$ for the sensible heat). However, once the atmospheric cooling is distributed into the Atlantic and Indian Oceans, the heat flux is directed from the two ocean basins into the overlying atmosphere due to the temperature gradient between the lower atmosphere and ocean (i.e. cooling for the ocean). Consequently, mean SST in the Atlantic and Indian Ocean cools. This additional process presented in the fully-coupled model experiments elucidates the inter-basin interaction of biological feedbacks and also emphasizes a possible role of the atmosphere in conveying the biological thermal impact in the Pacific to other tropical oceans.

So far, it has been shown that marine biology induces a decrease of mean SST in the eastern equatorial Pacific which is accompanied by the shoaling of thermocline and mixed layer. This can be seen in both the ocean-only model and fully-coupled model results. However, in the fullycoupled model, the amplitude of the decreased SST is stronger than the ocean-only model result. Also, the SST cooling in the eastern equatorial Pacific affects other oceans through the atmosphere-ocean heat flux change in the fully-coupled model.

\subsection{Influence of marine biology on the ENSO magnitude}

In addition to the biological impacts on the mean climate state, biological feedbacks can also alter SST variability in the tropical Pacific, such as the magnitude and skewness of ENSO (Timmermann and Jin 2002; Marzeion et al. 2005; Loptien et al. 2009; Jochum et al. 2010). As indicated in the introduction, whether the effect of chlorophyll amplifies or reduces the ENSO variability has not yet been resolved. Moreover, to date the authors are not aware of any studies examining the effect of atmosphere-ocean coupling on the relationship between marine biology and ENSO variability. In this section, we will examine the effect of chlorophyll on ENSO variability in both fullycoupled model experiments and ocean-only experiments, and thereby investigate the role of air-sea coupling.

First, the standard deviation (STDV) of the NINO3 SST are compared to each experiment to investigate the biological impact on ENSO magnitude (Fig. 8). Compared to the CHL.0, all the experiments with non-zero chlorophyll give considerably larger ENSO amplitudes for both fullycoupled model and ocean-only experiments. For example,

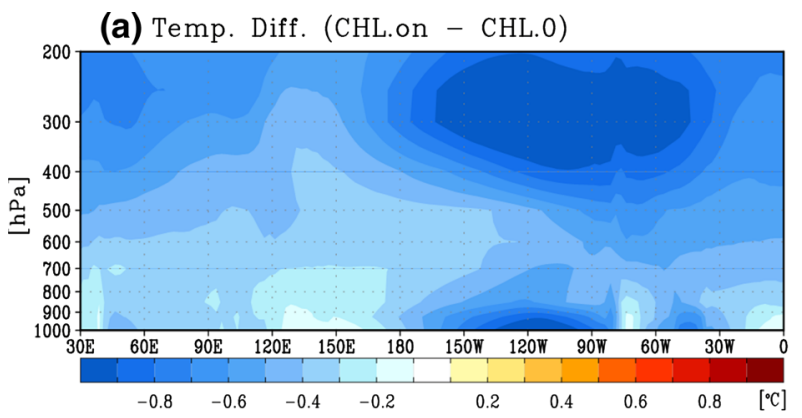

(b) LH \& SH Diff. (CHL.on - CHL.0)

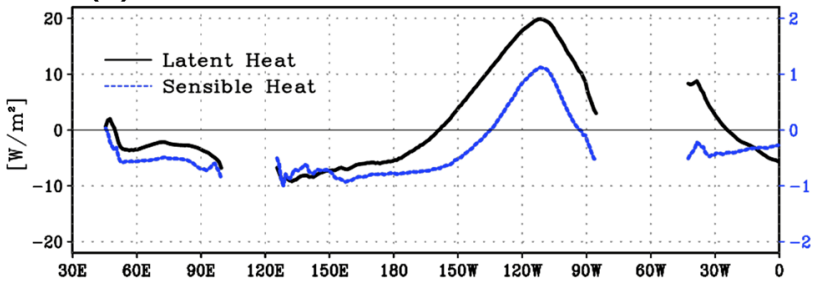

Fig. 7 Mean difference of the a atmospheric temperature above the equator, and the $\mathbf{b}$ latent heat flux and sensible heat flux averaged along the equator between CHL.on and CHL.0

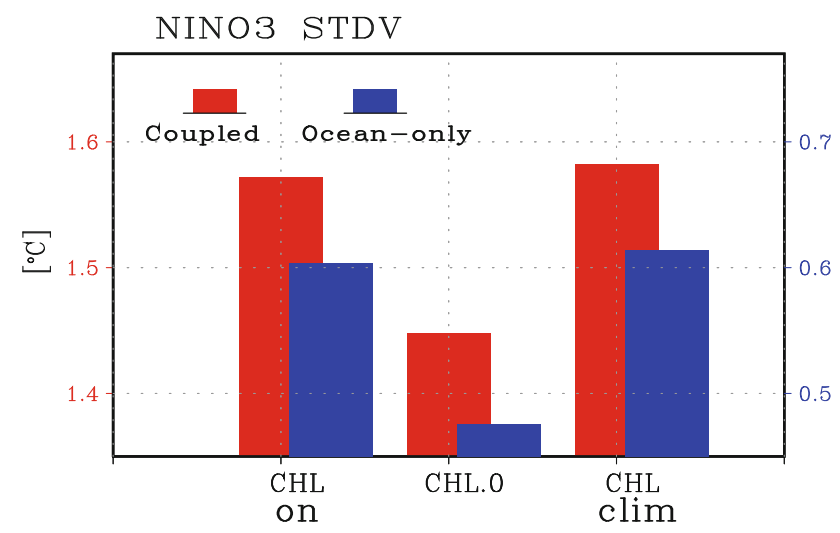

Fig. 8 Standard deviations of the SST in NINO3 region from the fully-coupled experiments (red bars; left $y$-axis) and the ocean-only experiments (blue bars; right $y$-axis) 
NINO3 STDV increases from $1.45{ }^{\circ} \mathrm{C}$ (CHL.0) to $1.58{ }^{\circ} \mathrm{C}$ (CHL.clim) in the case of fully-coupled model, and from $0.48{ }^{\circ} \mathrm{C}$ (CHL.0) to $0.61{ }^{\circ} \mathrm{C}$ (CHL.clim) in the case of ocean-only model. Note that the stronger NINO3 STDV in fully-coupled model experiments relative to the ocean-only model experiments might be caused by the weaker heat flux damping and stronger atmospheric feedbacks in the coupled model.

The enhanced ENSO variability with the presence of chlorophyll is linked with decreased mean thermocline depth as shown in Fig. 4c, d. According to previous studies, vertical displacement of the thermocline and the corresponding changes in vertical temperature advection are important factors influencing the SST tendency in the eastern equatorial Pacific (so-called thermocline feedback). Further, this feedback process can more easily influence the SST variations as the mean thermocline depth becomes shallower (Kang et al. 2004; An et al. 2008). Thus, the shoaling of the thermocline in CHL.on and CHL.clim relative to CHL.0 can have larger thermodynamic responses to wind forcing, and consequently, more strongly intensify the ENSO signal. Marzeion et al. (2005) mentioned that the increased ENSO variability due to chlorophyll is related to the reduced amplitude of the annual cycle caused by mixed layer deepening, but our results demonstrate that the simulated annual cycle in the eastern equatorial Pacific is amplified (not shown). Thus, we argue here that the intensified thermocline feedback associated with the thermocline shoaling may have a more important effect on the increased ENSO magnitude rather than the changes in the annual cycle. This explanation is consistent with two recent studies showing intensified ENSO magnitude (Loptien et al. 2009; Park et al. 2012). Particularly, for the oceanonly model experiments, the STDV of the NINO3 SST increases by more than $20 \%$ when the effects of chlorophyll are incorporated (blue bar in Fig. 8), and this matches the results of Park et al. (2012) that used the same OGCM from GFDL but with a slightly different experimental design.

In contrast to the significant changes in ENSO magnitude due to the mean chlorophyll, the comparison of interactively varying chlorophyll (CHL.on) to the climatologically fixed chlorophyll (CHL.clim) shows a relatively weak difference (Fig. 8). However, even though the differences are weak, they can be physically meaningful. Both fully-coupled model experiments and ocean-only experiments show a weakening of ENSO magnitude in the interactively varying chlorophyll experiments relative to the experiments with fixed chlorophyll. This result is in agreement with previous studies, emphasizing the role of direct thermal response to the bi-optical coupling (Timmermann and Jin 2002; Wetzel et al. 2006; Jochum et al. 2010). That is, the decreased surface chlorophyll during El
Niño induces anomalous surface cooling, while the increased chlorophyll during La Niña results in surface warming, both of which act to dampen the ENSO amplitude. However, the 1-3\% reduction in the ENSO variability simulated in our study is not as strong as that found by Wetzel et al. (2006) and Jochum et al. (2010), who reported 10-15 and 9\% smaller ENSO amplitudes, respectively.

One of key points here is that atmosphere-ocean coupling has an impact on the degree to which the bio-physical feedbacks alter the ENSO magnitude. In terms of the ENSO-amplifying impact of mean chlorophyll (comparing CHL.clim and CHL.0), the fully-coupled model shows only $\sim 10 \%$ stronger ENSO variability, while the oceanonly model shows ENSO variability is more than $20 \%$ stronger. One possible reason why the ENSO amplification effect by chlorophyll is reduced under the atmosphereocean coupling may be the smaller difference in the mean thermocline depth between CHL.clim and CHL.0 (cf. Fig. 4c, d). As explained above, smaller changes in thermocline depth generally induce weaker SST variability in the eastern equatorial Pacific.

Another potential cause may be the weakened atmospheric feedback. The cooler eastern Pacific SST (or the stronger east-west equatorial SST gradient) due to chlorophyll should reduce the atmospheric feedback in the fully-coupled model experiments. According to Zhang (1993), the intensity of convection activity is weaker when the SST is lower. The climatological weak convective

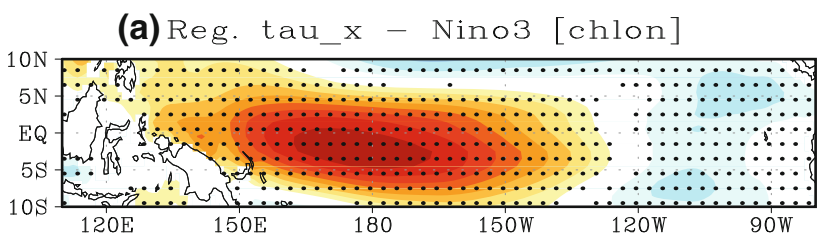

(b) Reg. tau_x - Nino3 [chlo]

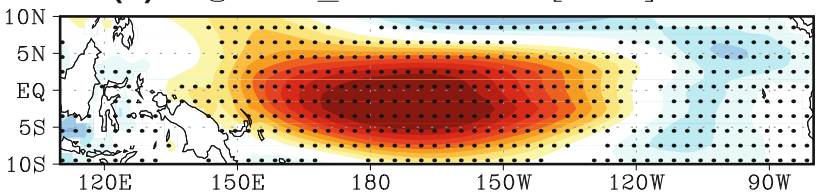

(c) Reg. tau_x - Nino3 [chlclim]

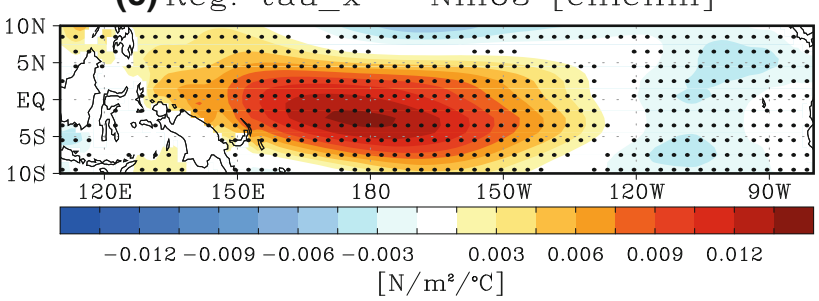

Fig. 9 Regressed zonal wind stress against the NINO3 SST derived from a CHL.on, b CHL.0, and c CHL.clim of fully-coupled experiments 
activity leads to weak atmospheric responses to SST forcing (Kim et al. 2011; Jang et al. 2013; Ham and Kug 2012; Kug et al. 2012; Watanabe et al. 2012). The weaker convective response to lower SST caused by chlorophyll reduces the Bjerkness feedback, and hence suppresses the role of the atmosphere on ENSO dynamics. The regressed zonal wind forcing onto the NINO3 SST (i.e. proxy for the strength of atmospheric feedback on ENSO) in the fullycoupled model experiments indicates weaker positive Bjerkness feedbacks in the experiments with chlorophyll relative to that without chlorophyll (Fig. 9). Note that, in the case of ocean-only model simulations, the net-effect of atmospheric feedback has been applied by prescribing the observational wind forcing.

Comparing the NINO3 SST STDV of the CHL.on with that of CHL.clim for both the fully-coupled and ocean-only models, it shows that the $\sim 2 \%$ damping effect on the ENSO magnitude by interactively varying chlorophyll for the ocean-only model is not intensified by the presence of atmospheric feedbacks in the fully-coupled model (Fig. 8). This result is somewhat surprising. In principle, the ENSO damping effect associated with the thermal response due to chlorophyll is expected to be stronger when accounting for the atmospheric feedback. It is because the damping effect reduces the anomalous east-west SST gradient in the equatorial Pacific, which would weaken the atmospheric feedback, and in turn should generate a larger damping effect on the ENSO amplitude. Based on the result of this study, however, the damping effect is still $\sim 2 \%$ of total ENSO magnitude in the fully-coupled model experiment. This may imply that direct biological heating is not strong enough to change the east-west SST gradient, and the corresponding atmospheric feedback in the equatorial Pacific.

In this subsection, it is found that both ENSO amplifying effect and ENSO damping effect due to the inclusion of chlorophyll exist in both ocean-only model and fully-coupled model experiments. In the fully-coupled model, however, the amplifying effect on ENSO appears to be weaker than in the ocean-only model due to the weakening of the atmospheric feedback.

\subsection{Influence of marine biology on the ENSO skewness}

In addition to the amplitude, the biological impact on the skewness of ENSO, which measures the asymmetry, is analyzed. It is known that the ENSO skewness is resulted from the atmospheric nonlinearity (Kang and Kug 2002) and oceanic nonlinearity (An and Jin 2004; Su et al. 2010; An et al. 2008). Similar to the effects on ENSO amplitude, there are two important features in the biologically-induced changes in the ENSO skewness. One is the increased ENSO skewness caused by effects of the mean chlorophyll
NINO3 Skewness

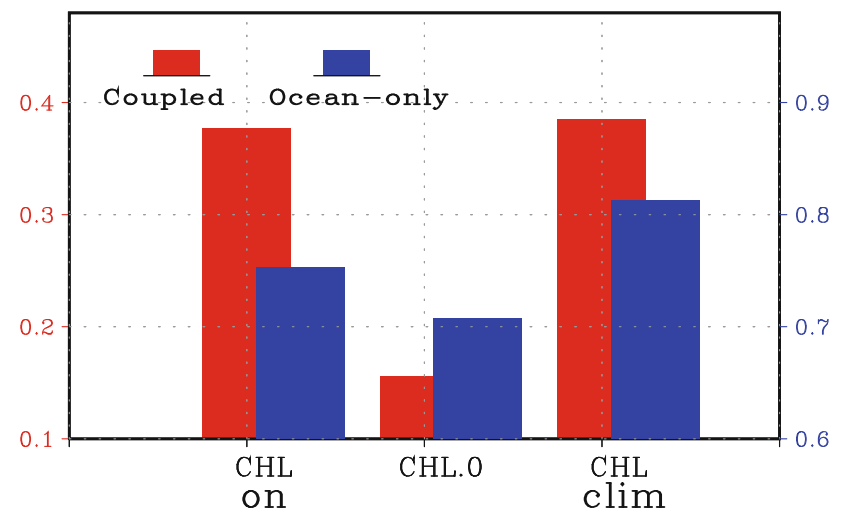

Fig. 10 Same as Fig. 7 but for skewness of NINO3 SST

and the other is the decreased ENSO skewness due to the effects of interactively varying chlorophyll. These features can be found in both the fully-coupled model and oceanonly model results.

First, comparing the experiments with and without chlorophyll, ENSO skewness tends to be higher with the presence of chlorophyll (Fig. 10). This is likely related to the relative effectiveness of the biologically-induced shoaling of the thermocline on the thermocline feedback. As mentioned above, the presence of chlorophyll enhances the thermocline shoaling in the eastern equatorial Pacific, which then intensifies the ENSO magnitude due to the stronger thermocline feedback. However, the effectiveness of this thermocline feedback is ENSO phase-dependent since the thermocline shoaling impact by mean chlorophyll is stronger in the warm phase than in the cold phase. This is because the thermocline depth in the eastern equatorial Pacific is shallow enough in a climatological mean sense, thus the additional biologically-induced shoaling of the thermocline depth cannot strongly affect the subsurface temperature during the La Niña state.

Figure 11 shows the slope of the subsurface temperature regressed against the NINO3-averaged, mean thermocline depth. Note that the subsurface temperature is averaged over $50-100 \mathrm{~m}$ depth, which is the typical thermocline depth range. The interactively varying (CHL.on) and the climatologically fixed chlorophyll (CHL.clim) experiments show very similar results for both the El Niño and La Niña phases of ENSO, which is probably due to similar mean thermocline depth in the NINO3 region for both phases (Fig. 4b). In comparison, the zero chlorophyll experiment (CHL.0) shows roughly a $25 \%$ weaker subsurface temperature response. This result reiterates the intensified thermocline feedback that occurs due to a shallower mean thermocline depth. A notable point here is that the difference of the regressed subsurface temperature between CHL.on (or CHL.clim) and CHL.0 in the El Niño phase is greater than the difference in the La Niña phase (Fig. 11). 


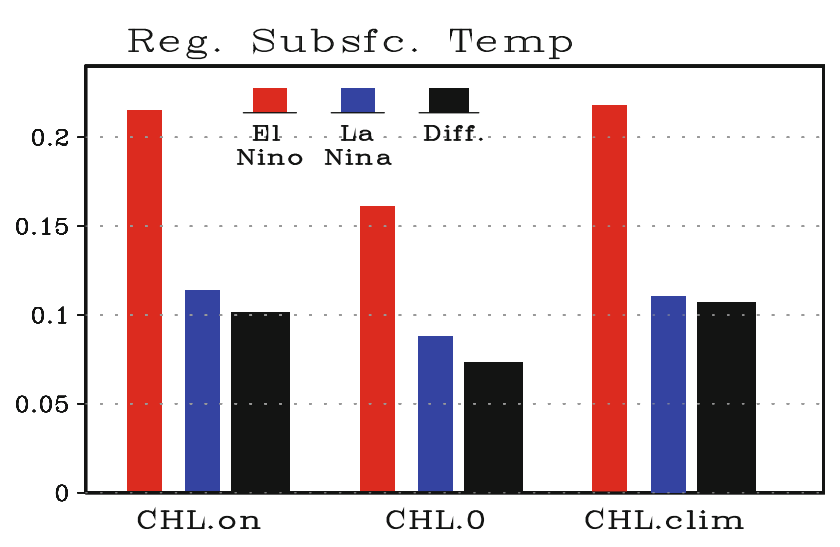

Fig. 11 Subsurface temperature (100-50 m depth-average) regressed against the thermocline depth averaged in NINO3 region. Red bar represents the regressed value in El_Niño, blue bar represents the one in La Niña case. Black bar is the difference between the regressed values of El Niño and La Niña

Consequently, the difference of the regressed subsurface temperature between El Niño and La Niña phases implies an asymmetric thermocline feedback that is larger in the experiments with chlorophyll than those without one (Black bars in Fig. 11). This result also implies that the biologically-induced thermocline feedback intensification during El Niño is stronger than that during La Niña. In other words, a change in depth of the deeper thermocline during the El Niño phase can be more effective in generating subsurface temperature responses than the same thermocline depth change does for the shallower thermocline depth during La Niña. Therefore, the mean chlorophyll concentrations prescribed or simulated in a model induce higher skewness of ENSO compared to simulations lacking chlorophyll.

Another point worth emphasizing is that the interactively varying chlorophyll (CHL.on) results in lower skewness than does the climatological result (CHL.clim), which is particularly notable in the ocean-only model experiments. The lower skewness in the interactively varying chlorophyll experiment (CHL.on) is presumably associated with the phase dependency of the ENSO damping effect which is related to the skewness of the chlorophyll concentration. In the ocean-only model, the chlorophyll skewness in NINO3 is -0.79 . Similar to previous studies, our result also shows that chlorophyll within the upper $50 \mathrm{~m}$ in the eastern equatorial Pacific decreases during El Niño and increases during La Niña (not shown). Thus, the negative skewness of chlorophyll simulated from CHL.on means that the chlorophyll decrease during the El Niño phase is stronger than the chlorophyll increase during the La Niña phase. Consequently, through biologicallyinduced direct heating the larger decrease in chlorophyll during El Niño is more effective to reduce positive SST anomalies than the opposite effects of increased chlorophyll on damping negative SST anomalies during La Niña, therefore, less skewness of ENSO amplitude occurs. In the fully-coupled model, however, chlorophyll skewness turns out to be -0.04 , which is consistent with a negligible decrease of the ENSO skewness in CHL.on relative to CHL.clim. Therefore, in CHL.on, the thermocline effect of the mean chlorophyll and the thermal heating effect of the interactively varying chlorophyll are competing with each other in affecting the skewness of ENSO, but the thermal heating effect seems to be minor in the fully-coupled model.

According to the bio-thermostat hypothesis proposed by Timmermann and Jin (2002), the interplay between ENSO and its biological feedback intensify the ENSO skewness. They emphasized that the ocean biological heating more strongly affects the La Niña phase than the El Niño phase due to the shallower mixed layer during La Niña. Given that the biologically-induced heat budget is the function of perturbations of both the mixed layer and chlorophyll concentrations, this study using fully coupled GCM coupled with a complex biogeochemical model suggests that not only does the phase-dependent heat capacity during ENSO introduce asymmetry, but the skewness of chlorophyll itself could also be another important factor influencing the asymmetry of ENSO.

\section{Summary and discussion}

In this study, the impact of the marine ecosystem on the physical and thermal dynamics of the tropical oceans has been investigated. This study is the first to illustrate the biological impact on ENSO in which both ocean-only and fully-coupled ocean-atmosphere models coupled to a complex marine biogeochemistry model are used to explore the conflicting results reported in previous studies. By conducting different experiments including two different control experiments prescribed by monthly climatological mean chlorophyll and zero chlorophyll (CHL.clim and CHL.0, respectively), this study draws the following findings.

Inclusion of marine biology (CHL.on and CHL.clim) leads to decreased mean SST in the eastern equatorial Pacific which is accompanied by the shoaling of thermocline and mixed layer. Consistent with previous studies, this is related to the vertical redistribution of shortwave heating and the resultant anomalous equatorial upwelling triggered by phytoplankton. It is found that the biologically-induced SST cooling in the eastern equatorial Pacific is amplified in the fully-coupled model experiments relative to the ocean-only model experiments. This is because the increased east-west SST contrast strengthens the trade 
wind field, which in turn intensifies the equatorial upwelling.

The biologically-triggered SST cooling in the eastern equatorial Pacific affects other oceans in the fully-coupled experiments through changes in the heat flux transported within the tropical atmosphere. That is, the cold SST suppresses the release of latent and sensible heat, which in turn induces an atmospheric cooling. The moisture-related atmospheric cooling is quickly distributed throughout the tropical troposphere; which induces the Atlantic and Indian Ocean to release more heat into the atmosphere (i.e. cooling at the ocean surface over these two oceans) to balance the atmospheric cooling above them. This fullycoupled ocean-atmosphere result implies that such biologically-induced inter-basin feedbacks can modify (or outweigh) the local biological heating effect, and consequently, modulate the regional climate response. These effects cannot be captured in ocean-only model experiments.

Simulated chlorophyll in CHL.on affects the ENSO magnitude by two different processes. One is the ENSO amplifying effect of the mean chlorophyll, which is caused by the intensified thermocline feedback due to the thermocline shoaling. The other process is the ENSO damping effect, which arises from anomalous biological warming (cooling) during La Niña (El Niño) due to the interactively varying chlorophyll levels coupled with the physical model response. The amplifying effect of the biological feedback on ENSO appears to be weaker in the fully-coupled model experiments relative to the ocean-only experiments. We found that the weakening of the atmospheric feedback is related to the lower mean SST and the resultant dry condition, which is responsible for the reduction of the ENSO amplifying effect in the fully-coupled model.

The inclusion of biological feedback effects also impact the skewness of ENSO. The impact of mean chlorophyll tends to increase the ENSO skewness primarily due to the asymmetric oceanic response during El Niño and La Niña to a given biological impact. This occurs because the thermocline feedback associated with the ENSO amplifying effect works more effectively during the El Niño phase than the La Niña phase. In contrast, the impact of interactively varying chlorophyll reduces the ENSO skewness, presumably due to the fact that biological cooling during El Niño is stronger than the opposite phase biological heating during La Niña.

As mentioned earlier, different modeling studies on the bio-physical feedbacks in the tropical oceans reported different results not only on tropical mean state but on tropical climate variability. Some of previous studies briefly discussed that the conflicting results are likely attributed to differences in the experimental designs like whether they include atmospheric feedbacks as well as biological feedbacks within ocean. (Marzeion et al. 2005; Lengaigne et al. 2007). However, as indicated in Table 1, the response of tropical mean SST to the bio-optical feedbacks is not consistent even among the models commonly enabling air-sea coupling. Thus, the discrepancy cannot be explained simply by the presence or absence of atmosphere-ocean coupling. Indeed, results of this study show that mean SST in the eastern equatorial Pacific decreases in both fully-coupled model and ocean-only model experiment after including marine biology. The atmosphere-ocean coupling just acts to amplify the biologically-induced mean change through a positive atmospheric feedback, but does not change the sign of the response. Additionally, fully-coupled and ocean-only models produce consistent results in terms of ENSO variability as well. Thus, the different results of the bio-physical feedbacks in previous studies might arise from other factors, such as different spatial patterns of chlorophyll simulated in different biogeochemical models, various settings to determine the attenuation depth used in control experiments, and the sensitivity of the oceanic response to the biologically-induced differential heating due to uncertainties in the parameterization of tropical convection. For example, given that the horizontal and vertical structure of chlorophyll is acknowledged to play a large role in the response to biological feedback (Lengaigne et al. 2007; Anderson et al. 2009; Gnanadesikan and Anderson 2009), differences in the chlorophyll distribution shown in previous studies may explain the diversity of the model responses. If this is the case, a realistic simulation of the 3-dimensional structure of chlorophyll should be precomputed and validated against the observed distribution. To conclude, overall results suggest that more attention to be paid to explain such inter-model discrepancy.

Due to the significant role of atmosphere-ocean interactions in determining the tropical Pacific SST, previous studies often argued that the atmospheric feedback should always be included when investigating the biological impacts and only limited insight can be obtained from ocean-only model experiments. Indeed, this study shows that the atmospheric feedbacks do intensify the biologically-induced cooling of the mean SST in the eastern equatorial Pacific. However, such a strong atmospheric role does not hold true for ENSO variability. The biologicallyinduced change in the amplitude or skewness of ENSO simulated from the fully-coupled model is not dramatically different from experiments without active atmospheric feedback as shown in this study. Strengthening of ENSO amplitude and skewness by the mean chlorophyll and the weakening of them by interactively varying chlorophyll are observed both in the fully-coupled and ocean-only models. One interesting point is that the ENSO damping effect of interannually varying chlorophyll has not been intensified 
even with atmospheric Bjerknes feedback. One can expect that the damped ENSO variability can reduce the east-west temperature gradient, which consequently weakens the Bjerknes feedback, leading to a larger damping effect on ENSO amplitude relative to ocean-only simulations. In the GFDL model used here, however, the atmospheric role seems to be relatively minor presumably due to a weak biological thermal heating effect altering the atmospheric circulation over the tropics. Of course, a direct comparison between experiments with and without a coupled atmospheric model should be carefully undertaken because the mean SST and the atmospheric feedback are different in individual experiments. But it is at least our conclusion that the use of a forced ocean model with a fixed atmospheric feedback could be an effective choice for understanding the complicated bio-physical feedback process to avoid some of the complexity of the fully-coupled ocean-atmosphere model.

As far as the tropical Pacific is concerned, the biological impacts on the mean and variability of tropical climate are quite similar between CHL.on and CHL.clim in the fullycoupled model. As claimed by Jochum et al. (2010), some form of biogeochemistry model is necessary to correctly capture the bio-physical feedback that causes significant damping of ENSO in the fully-interactive experiment relative to the prescribed experiment. In the GFDL model used here, however, such phytoplankton-ENSO feedback seems to be much less effective relative to the feedback due to mean phytoplankton. In general, the experiment with fully-coupled biogeochemistry is computationally expensive so that prescribing the biological properties in a CGCM could be an efficient way to investigate biological impacts on the tropical climate. Nevertheless, with respect to the biogeochemical feedback by phytoplankton modulating atmospheric $\mathrm{CO}_{2}$ through photosynthesis and affecting the atmospheric water vapor through the modification of tropical convection, the use of a fully interactive and costly biogeochemistry model linked to a fully coupled ocean-atmosphere GCM should be considered in the projections of global climate change scenarios.

Acknowledgments This work was supported by the National Research Foundation of Korea Grant Funded by Korean Government (MEST) (NRF-2009-C1AAA001-2009-0093).

\section{References}

Alexander M, Scott J (2002) The influence of ENSO on air-sea interaction in the Atlantic. Geophys Res Lett 29(14). doi:10. $1029 / 2001 \mathrm{~g} 1014347$

An SI, Jin F (2004) Nonlinearity and Asymmetry of ENSO. J Clim 17(12):2399-2412. doi:10.1175/1520-0442(2004)017<2399: NAAOE $>2.0 . \mathrm{CO} ; 2$
An SI, Kug JS, Ham YG, Kang IS (2008) Successive modulation of ENSO to the future greenhouse warming. J Clim 21(1):3-21. doi:10.1175/2007jcli1500.1

Anderson WG, Gnanadesikan A, Hallberg R, Dunne J, Samuels BL (2007) Impact of ocean color on the maintenance of the Pacific Cold Tongue. Geophys Res Lett 34(11). doi:10.1029/ 2007g1030100

Anderson W, Gnanadesikan A, Wittenberg A (2009) Regional impacts of ocean color on tropical Pacific variability. Ocean Science 5(3):313-327

Ballabrera-Poy J, Murtugudde R, Zhang RH, Busalacchi AJ (2007) Coupled ocean-atmosphere response to seasonal modulation of ocean color: impact on interannual climate simulations in the tropical Pacific. J Clim 20(2):353-374. doi:10.1175/jcli3958.1

Behrenfeld MJ et al (2001) Biospheric primary production during an ENSO transition. Science 291(5513):2594-2597

Bretherton CS, Sobel AH (2003) The Gill model and the weak temperature gradient approximation. J Atmos Sci 60(2): 451-460. doi:10.1175/1520-0469(2003)060<0451:tgmatw $>2.0$. co; 2

Campbell JW (1995) The lognormal distribution as a model for biooptical variability in the sea. J Geophys Res 100(C7): 13237-13254

Chavez FP, Strutton PG, Friederich CE, Feely RA, Feldman GC, Foley DC, McPhaden MJ (1999) Biological and chemical response of the equatorial Pacific Ocean to the 1997-98 El Nino. Science 286(5447):2126-2131

Chiang JCH, Sobel AH (2002) Tropical tropospheric temperature variations caused by ENSO and their influence on the remote tropical climate. J Clim 15(18):2616-2631. doi:10.1175/15200442(2002)015<2616:tttvcb $>2.0 . \mathrm{co} ; 2$

Dunne JP, Murray JW, Aufdenkampe AK, Blain S, Rodier M (1999) Silicon-nitrogen coupling in the equatorial Pacific upwelling zone. Global Biogeochem Cycles 13(3):715-726. doi:10.1029/ 1999gb900031

Dunne JP, Armstrong RA, Gnanadesikan A, Sarmiento JL (2005) Empirical and mechanistic models for the particle export ratio. Global Biogeochem Cycle 19(4). doi:10.1029/2004gb002390

Esaias WE et al (1998) An overview of MODIS capabilities for ocean science observations. IEEE Trans Geosci Remote Sens 36(4): $1250-1265$

Field CB, Behrenfeld MJ, Randerson JT, Falkowski P (1998) Primary production of the biosphere: integrating terrestrial and oceanic components. Science 281(5374):237-240

Geider RJ, MacIntyre HL, Kana TM (1996) A dynamic model of photoadaptation in phytoplankton. Limnol Oceanogr 41(1):1-15

Gildor H, Naik NH (2005) Evaluating the effect of interannual variations of surface chlorophyll on upper ocean temperature. J Geophys Res 110(C7). doi:10.1029/2004jc002779

Ginoux P, Chin M, Tegen I, Prospero JM, Holben B, Dubovik O, Lin SJ (2001) Sources and distributions of dust aerosols simulated with the GOCART model. J Geophys Res 106(D17): 20255-20273. doi:10.1029/2000jd000053

Gnanadesikan A, Anderson WG (2009) Ocean water clarity and the ocean general circulation in a coupled climate model. J Phys Ocean 39(2):314-332. doi:10.1175/2008jpo3935.1

Gnanadesikan A, Dunne JP, John J (2011) What ocean biogeochemical models can tell us about bottom-up control of ecosystem variability. ICES J Mar Sci 68(6):1030-1044. doi:10.1093/ icesjms/fsr098

Griffies SM, Schmidt M, Herzfeld M (2009) Elements of mom4p1. GFDL Ocean Group Tech Rep 6:444

Ham Y-G, Kug J-S (2012) How well do current climate models simulate two-types of El Nino? Clim Dyn 39:383-398. doi:10. 1007/s00382-011-1157-3 
Henson SA, Dunne JP, Sarmiento JL (2009) Decadal variability in North Atlantic phytoplankton blooms. J Geophys Res 114:C04013. doi:10.1029/2008jc005139

Jang Y-S, Kim D, Kim Y-H, Kim D-H, Watanabe M, Jin F-F, Kug J-S (2013) Simulation of two types of El Nino from different convective parameters. Asia-Pacific J Atmos Sci 49(2):193-199. doi:10.1007/s13143-013-0020-3

Jochum M, Yeager S, Lindsay K, Moore K, Murtugudde R (2010) Quantification of the feedback between phytoplankton and ENSO in the community climate system model. J Clim 23(11):2916-2925. doi:10.1175/2010jcli3254.1

Kalnay E et al (1996) The NCEP/NCAR 40-year reanalysis project. Bull Am Meteorol Soc 77(3):437-471

Kang I-S, Kug J-S (2002) El Nino and La Nina sea surface temperature anomalies: asymmetry characteristics associated with their wind stress anomalies. J Geophy Res 107(D19):4372

Kang IS, Kug JS, An SI, Jin FF (2004) A near-annual Pacific Ocean basin mode. J Clim 17(12):2478-2488. doi:10.1175/15200442(2004)017<2478:anpobm>2.0.co;2

Kim D, Jang Y-S, Kim D-H, Kim Y-H, Watanabe M, Jin F-F, Kug J-S (2011) El Niño-Southern Oscillation sensitivity to cumulus entrainment in a coupled general circulation model. J Geophys Res 116:D22112. doi:10.1029/2011JD016526

Kug J-S, Ham Y-G, Lee J-Y, Jin F-F (2012) Improved simulation of two types of El Niño in CMIP5 models. Environ Res Lett 7. doi:10.1088/1748-9326/7/3/039502

Large W, Yeager S (2004) Diurnal to decadal global forcing for ocean and sea-ice models: the data sets and flux climatologies. Report on National Centre for Atmospheric Research, Boulder, CO

Lengaigne M, Menkes C, Aumont O, Gorgues T, Bopp L, Andre JM, Madec G (2007) Influence of the oceanic biology on the tropical Pacific climate in a coupled general circulation model. Clim Dyn 28(5):503-516. doi:10.1007/s00382-006-0200-2

Lewis MR, Carr ME, Feldman GC, Esaias W, McClain C (1990) Influence of penetrating solar-radiation on the heat-budget of the equatorial Pacific-ocean. Nature 347(6293):543-545

Lin PF, Liu HL, Zhang XH (2007) Sensitivity of the upper ocean temperature and circulation in the equatorial pacific to solar radiation penetration due to phytoplankton. Adv Atmos Sci 24:765-780

Lin PF, Liu HL, Zhang XH (2008) Effect of chlorophyll-a horizontal distribution on upper ocean temperature in the central and eastern equatorial Pacific. Adv Atmos Sci 25:585-596

Lin PF, Liu HL, Yu YQ, Zhang XH (2011) Response of Sea surface temperature to chlorophyll-a concentration in the tropical Pacific: annual mean, seasonal cycle and interannual variability. Adv Atmos Sci 28:492-510

Loptien U, Eden C, Timmermann A, Dietze H (2009) Effects of biologically induced differential heating in an eddy-permitting coupled ocean-ecosystem model. J Geophys Res 114:C06011. doi:10.1029/2008jc004936

Maes C, Sudre J, Garcon V (2010) Detection of the eastern edge of the equatorial pacific warm pool using satellite-based ocean color observations. Sola 6:129-132. doi:10.2151/sola.2010-033

Manizza M, Le Quéré C, Watson AJ, Buitenhuis ET (2005) Biooptical feedbacks among phytoplankton, upper ocean physics and sea-ice in a global model. Geophys Res Lett 32:L05603

Martin JH et al (1994) Testing the iron hypothesis in ecosystems of the equatorial Pacific Ocean. Nature 371(6493):123-129. doi:10. 1038/371123a0

Marzeion B, Timmermann A, Murtugudde R, Jin FF (2005) Biophysical feedbacks in the tropical Pacific. J Clim 18(1): 58-70. doi:10.1175/jcli3261.1

McClain CR, Cleave ML, Feldman GC, Gregg WW, Hooker SB, Kuring N (1998) Science quality SeaWiFS data for global biosphere research. Sea Technol 39(9):10-16
Morel A (1988) Optical modeling of the upper ocean in relation to its biogenous matter content (Case I Waters). J Geophys Res 93(C9):10749-10768. doi:10.1029/JC093iC09p10749

Morel A, Berthon JF (1989) Surface pigments, algal biomass profiles, and potential production of the euphotic layer: relationships reinvestigated in view of remote-sensing applications. Limnol Oceanogr 34(8):1545-1562

Murray RJ (1996) Explicit generation of orthogonal grids for ocean models. J Comput Phys 126(2):251-273

Murtugudde R, Beauchamp J, McClain CR, Lewis M, Busalacchi AJ (2002) Effects of penetrative radiation on the upper tropical ocean circulation. J Clim 15(5):470-486. doi:10.1175/15200442(2002)015<0470:eoprot $>2.0$. co; 2

Nakamoto S, Kumar SP, Oberhuber JM, Muneyama K, Frouin R (2000) Chlorophyll modulation of sea surface temperature in the Arabian Sea in a mixed-layer isopycnal general circulation model. Geophys Res Lett 27(6):747-750. doi:10.1029/1999g1002371

Nakamoto S, Kumar SP, Oberhuber JM, Ishizaka J, Muneyama K, Frouin R (2001) Response of the equatorial Pacific to chlorophyll pigment in a mixed layer isopycnal ocean general circulation model. Geophys Res Lett 28(10):2021-2024. doi: $10.1029 / 2000 \mathrm{~g} 1012494$

Ohlmann JC (2003) Ocean radiant heating in climate models. J Clim 16(9):1337-1351. doi:10.1175/1520-0442-16.9.1337

Park JY, Kug JS, Park J, Yeh SW, Jang CJ (2011) Variability of chlorophyll associated with El Niño-Southern Oscillation and its possible biological feedback in the equatorial Pacific. J Geophys Res 116:C10001. doi:10.1029/2011jc007056

Park JY, Kug JS, Park YG (2012) A modeling study on bio-physical processes associated with ENSO. Prog Oceanogr (submitted)

Patara L, Vichi M, Masina S, Fogli PG, Manzini E (2012) Global response to solar radiation absorbed by phytoplankton in a coupled climate model. Clim Dyn 39(7-8):1951-1968. doi:10. 1007/s00382-012-1300-9

Paulson CA, Simpson JJ (1977) Irradiance measurements in the upper ocean. J Phys Oceanogr 7(6):952-956

Picaut J, Ioualalen M, Delcroix T, Masia F, Murtugudde R, Vialard J (2001) The oceanic zone of convergence on the eastern edge of the Pacific warm pool: A synthesis of results and implications for El Niño-Southern Oscillation and biogeochemical phenomena. J Geophys Res 106(C2):2363-2386

Radenac MH, Leger F, Singh A, Delcroix T (2012) Sea surface chlorophyll signature in the tropical Pacific during eastern and central Pacific ENSO events. J Geophys Res 117. doi:10.1029/ $2011 \mathrm{jc} 007841$

Runge JA, Plourde S, Joly P, Niehoff B, Durbin E (2006) Characteristics of egg production of the planktonic copepod, Calanus finmarchicus, on Georges Bank: 1994-1999. Deep-Sea Res Part II 53(23-24):2618-2631. doi:10.1016/j.dsr2.2006.08.010

Sathyendranath S, Gouveia AD, Shetye SR, Ravindran P, Platt T (1991) Biological control of surface temperature in the Arabian Sea. Nature 349(6304):54-56. doi:10.1038/349054a0

Smith TM, Reynolds RW, Peterson TC, Lawrimore J (2008) Improvements to NOAA's historical merged land-ocean surface temperature analysis (1880-2006). J Clim 21(10):2283-2296. doi:10.1175/2007jcli2100.1

Sobel AH, Held IM, Bretherton CS (2002) The ENSO signal in tropical tropospheric temperature. J Clim 15(18):2702-2706. doi:10.1175/1520-0442(2002)015<2702:tesitt >2.0.co;2

Strutton PG, Chavez FP (2004) Biological heating in the equatorial Pacific: observed variability and potential for real-time calculation. J Clim 17(5):1097-1109. doi:10.1175/1520-0442(2004) 017<1097:bhitep $>2.0$. co;2

Su J, Zhang R, Li T, Rong X, Kug J-S, Hong C-C (2010) Causes of the El Niño and La Niña amplitude asymmetry in the equatorial eastern Pacific. J Clim 23:605-617 
Sweeney C, Gnanadesikan A, Griffies SM, Harrison MJ, Rosati AJ, Samuels BL (2005) Impacts of shortwave penetration depth on large-scale ocean circulation and heat transport. J Phys Ocean 35(6):1103-1119. doi:10.1175/jpo2740.1

Timmermann A, Jin FF (2002) Phytoplankton influences on tropical climate. Geophys Res Lett 29(23). doi:10.1029/2002g1015434

Turner AG, Joshi M, Robertson ES, Woolnough SJ (2011) The effect of Arabian Sea optical properties on SST biases and the South Asian summer monsoon in a coupled GCM. Clim Dyn 1-16. doi:10.1007/s00382-011-1254-3

Watanabe M, Kug J-S, Jin F-F, Collins M, Ohba M, Wittenburg A (2012) Uncertainty in the ENSO amplitude change from the past to the future. Geophys Res Lett 39:L20703. doi:10.1029/ 2012GL053305

Wetzel P, Maier-Reimer E, Botzet M, Jungclaus J, Keenlyside N, Latif M (2006) Effects of ocean biology on the penetrative radiation in a coupled climate model. J Clim 19(16):3973-3987. doi: $10.1175 /$ jcli3828.1
Wilson C, Coles VJ (2005) Global climatological relationships between satellite biological and physical observations and upper ocean properties. J Geophys Res 110(C10). doi:10.1029/ 2004jc002724

Yoder JA, Kennelly MA (2003) Seasonal and ENSO variability in global ocean phytoplankton chlorophyll derived from 4 years of SeaWiFS measurements. Global Biogeochem Cycles 17(4): 1112. doi: $10.1029 / 2002 \mathrm{gb} 001942$

Zhang CD (1993) Large-scale variability of atmospheric deep convection in relation to sea-surface temperature in the tropics. J Clim 6(10):1898-1913

Zhang RH, Busalacchi AJ, Wang XJ, Ballabrera-Poy J, Murtugudde RG, Hackert EC, Chen D (2009) Role of ocean biology-induced climate feedback in the modulation of E1 Niño-Southern Oscillation. Geophys Res Lett 36. doi:10.1029/2008g1036568 